Nov 17]. Available from: https://www.cdc.gov/nchhstp/newsroom/2017/HIVContinuum-of-Care.html.

2. Lohse N, Obel N. Update of survival for persons with HIV infection in Denmark. Ann Intern Med 2016;165:749-750.

3. Neuhaus J, Jacobs DR Jr, Baker JV, Calmy A, Duprez D, La Rosa A, et al. Markers of inflammation, coagulation, and renal function are elevated in adults with HIV infection. J Infect Dis 2010;201:1788-1795.

4. Cowell A, Shenoi SV, Kyriakides TC, Friedland G, Barakat LA. Trends in hospital deaths among human immunodeficiency virus-infected patients during the antiretroviral therapy era, 1995 to 2011. J Hosp Med 2015;10:608-614.

5. Smith CJ, Ryom L, Weber R, Morlat P, Pradier C, Reiss P, et al.; D:A:D Study Group. Trends in underlying causes of death in people with HIV from 1999 to 2011 (D:A:D): a multicohort collaboration. Lancet 2014;384:241-248.

6. Antiretroviral Therapy Cohort Collaboration. Survival of HIV-positive patients starting antiretroviral therapy between 1996 and 2013: a collaborative analysis of cohort studies. Lancet HIV 2017;4:e349-e356.

7. Hsue PY, Hunt PW, Ho JE, Farah HH, Schnell A, Hoh R, et al. Impact of HIV infection on diastolic function and left ventricular mass. Circ Heart Fail 2010;3:132-139.

8. Hsu JC, Li Y, Marcus GM, Hsue PY, Scherzer R, Grunfeld C, et al. Atrial fibrillation and atrial flutter in human immunodeficiency virus-infected persons: incidence, risk factors, and association with markers of HIV disease severity. J Am Coll Cardiol 2013;61:2288-2295.

9. Hsue PY, Deeks SG, Farah HH, Palav S, Ahmed SY, Schnell A, et al. Role of HIV and human herpesvirus-8 infection in pulmonary arterial hypertension. AIDS 2008;22:825-833.
10. Sitbon O, Lascoux-Combe C, Delfraissy JF, Yeni PG, Raffi F, De Zuttere D, et al. Prevalence of HIV-related pulmonary arterial hypertension in the current antiretroviral therapy era. Am J Respir Crit Care Med 2008;177:108-113.

11. Brittain EL, Duncan MS, Chang J, Patterson OV, DuVall SL, Brandt CA, et al. Increased echocardiographic pulmonary pressure in HIV-infected and -uninfected individuals in the Veterans Aging Cohort Study. Am J Respir Crit Care Med 2018; 197:923-932.

12. Galiè N, Humbert M, Vachiery JL, Gibbs S, Lang I, Torbicki A, et al. 2015 ESC/ERS Guidelines for the diagnosis and treatment of pulmonary hypertension: the Joint Task Force for the Diagnosis and Treatment of Pulmonary Hypertension of the European Society of Cardiology (ESC) and the European Respiratory Society (ERS): Endorsed by: Association for European Paediatric and Congenital Cardiology (AEPC), International Society for Heart and Lung Transplantation (ISHLT). Eur Heart J 2016;37:67-119.

13. Newman JH, Rich S, Abman SH, Alexander JH, Barnard J, Beck GJ, et al. Enhancing insights into pulmonary vascular disease through a precision medicine approach: a joint NHLBI-Cardiovascular Medical Research and Education Fund Workshop Report. Am J Respir Crit Care Med 2017;195:1661-1670.

Copyright (C) 2018 by the American Thoracic Society

\title{
Is It Time to Consider Obstructive Sleep Apnea Syndrome a Risk Factor for Alzheimer's Disease?
}

Obstructive sleep apnea syndrome (OSAS) is a highly prevalent sleep disorder that has several consequences. As was recently documented, the prevalence of moderate-to-severe sleep-disordered breathing $(\geqslant 15$ events $/ \mathrm{h}$ ) is $23.4 \%$ in women and $49.7 \%$ in men (1). These data, from a population-based study in Switzerland, reveal the real incidence of OSAS in the general population. OSAS has been consistently demonstrated to be a clinically relevant chronic sleep disorder characterized by recurrent episodes of upper-airway obstruction causing intermittent hypoxemia and hypercapnia, brain cortical microarousals and sleep fragmentation, increased inflammation, and oxidative stress (2). These features of OSAS have significant cardiovascular, neurocognitive, and metabolic consequences. Consequently, OSAS has been independently associated with several disorders, including hypertension, diabetes, metabolic syndrome, osteoporosis, and cardiovascular diseases (3-7). Moreover, OSAS has been identified as a risk factor for the development of Alzheimer's disease $(\mathrm{AD})$ dementia (8).

Sleep disorders are currently being investigated as possible pathogenic factors that trigger neurodegenerative disorders, with particular attention being paid to their effects on $\mathrm{AD}$ pathology. The recent identification of the glymphatic system has led researchers to investigate the association between sleep and the risk of neurodegeneration (9). The group led by Ricardo S. Osorio has focused over the past few years on the interconnections between OSAS and $\mathrm{AD}$ pathology in populations of cognitively normal elderly individuals $(10,11)$. As a result of their investigations, OSAS

Originally Published in Press as DOI: 10.1164/rccm.201710-2105ED on January 26, 2018 was demonstrated to be responsible for cerebrospinal fluid (CSF) AD biomarker changes in the elderly (10). Moreover, they showed that OSAS is associated not only with a pathological reduction of CSF $\beta$-amyloid ${ }_{42}\left(A \beta_{42}\right)$ levels but also with a continuing cognitive decline in the elderly (11). This evidence has been supported by further research, and it has been hypothesized that OSAS alters brain $\beta$-amyloid metabolism and promotes amyloid plaque deposition $(12,13)$. Therefore, the recent scientific literature has identified OSAS as a possible risk factor for $\mathrm{AD}$ neurodegeneration $(12,13)$.

The study by Sharma and colleagues (pp. 933-943) in this issue of the Journal represents an important milestone in this field (14). The authors first performed a longitudinal study analyzing the effect of OSAS on both CSF $A \beta_{42}$ levels and brain amyloid burden in cognitively normal elderly subjects. Specifically, a large population of cognitively intact people (55-90 yr old) underwent OSAS monitoring by home polygraphic recording, followed by lumbar puncture for CSF biomarker analysis ( $A \beta_{42}$ and tau protein levels), and/or Pittsburgh compound positron emission tomography scans to detect brain amyloid deposition. These assessments were longitudinally repeated in a subgroup of subjects who underwent follow-up investigations. The main result of this study was the direct correlation observed between the annual rate of change of CSF $A \beta_{42}$ concentrations and the apnea-hypopnea index. Secondarily, the authors confirmed that OSAS is a frequent diagnosis in adult and older people, as it affected $53 \%$ of the entire cognitively normal community-dwelling cohort. Moreover, the authors proved that the apnea-hypopnea index has a more significant association with the longitudinal change of $\beta$-amyloid measures than the apolipoprotein E4 genotype, which is currently 
considered one of the most important risk factors for sporadic AD. Finally, considering that not all patients have cognitive deterioration or brain magnetic resonance imaging structure pathological changes, the authors concluded that CSF $A \beta_{42}$ longitudinally decreases before the occurrence of signs or symptoms of AD. Notwithstanding the novelty of their results, the authors' explanation for the association between OSAS and $\mathrm{AD}$ is still speculative. However, different mechanisms that affect brain $\beta$-amyloid dynamics and thus induce AD pathological changes have been recognized in OSAS patients. In keeping with this observation, not only dysregulation of the glymphatic system but also intermittent hypoxemia, sleep fragmentation, slow-wave sleep impairment, synaptic dysfunction, brain inflammation, and Valsalva maneuvers (related to apnea events) may concurrently impair $\beta$-amyloid metabolism and clearance, causing the initial reduction of CSF $A \beta_{42}$ levels and subsequently the brain deposition of $\beta$-amyloid plaques (8-14).

These findings highlight the importance of diagnosing OSAS in late life, because it can pathologically change brain $\beta$-amyloid metabolism and subsequently induce AD neurodegeneration. It has been consistently demonstrated that CSF $A \beta_{42}$ levels decrease several years before brain magnetic resonance imaging structural changes and cognitive decline occur, supporting the hypothesis that OSAS may alter AD biomarkers in preclinical stages, which represent a possible temporal window in which therapeutic interventions may significantly change the course of the disease.

As a consequence, OSAS may be considered a risk factor for $\mathrm{AD}$. However, in contrast to other demonstrated risk factors for the development of $\mathrm{AD}$, this disorder can be treated by clinical interventions that are currently available in clinical practice. OSAS is easily treated by continuous positive airway pressure (CPAP), which usually ameliorates OSAS symptoms (15). In a recent investigation, the results of neuropsychological testing, CSF AD biomarkers, and sleep architecture were compared between untreated patients with OSAS and CPAP-treated patients with OSAS (15). Significantly, no signs of $\mathrm{AD}$ pathology were documented in the CPAP-treated patients, whereas CSF $A \beta_{42}$ levels were pathologically reduced in more than half of the untreated patients. Therefore, it was presumed that OSAS is associated with early but possibly modifiable $\mathrm{AD}$ biomarker changes (15). In support of this hypothesis, a very recent report documented the case of a middle-aged man who was affected by subjective cognitive decline coupled with OSAS (16). The subject underwent a lumbar puncture that revealed pathological CSF $A \beta_{42}$ levels, but had normal Pittsburgh compound and 2-deoxy-2-(18F) fluoro-D-glucose positron emission tomography scans. After CPAP treatment was initiated, the patient was followed for 1 year, with resolution of subjective cognitive complaints and normalization of CSF $\mathrm{A} \beta_{42}$ concentrations. This case report has opened new horizons for considering $\mathrm{AD}$ biomarkers as changeable if treatment is initiated in the preclinical stage of the disease, when CSF $\beta$-amyloid metabolism and clearance are altered but brain $\beta$-amyloid plaques have not yet been deposited.

In conclusion, the impressive data published by Osorio and colleagues, coupled with recent observations presented in the literature, suggest a new direction in considering OSAS as a trigger factor for the development of AD. The next step is to verify in randomized clinical trials that CPAP treatment can prevent or reverse pathological changes in $\mathrm{AD}$ biomarkers during the preclinical stages of the disease, as alterations in $\beta$-amyloid brain clearance occur earlier than plaque accumulation, neuronal dysfunction, and clinical symptoms.

Author disclosures are available with the text of this article at www.atsjournals.org.

Claudio Liguori, M.D.

Fabio Placidi, Ph.D.

Department of Systems Medicine

University of Rome "Tor Vergata"

Rome, Italy

\section{References}

1. Heinzer R, Vat S, Marques-Vidal P, Marti-Soler H, Andries D, Tobback $\mathrm{N}$, et al. Prevalence of sleep-disordered breathing in the general population: the HypnoLaus study. Lancet Respir Med 2015;3:310-318.

2. Durán J, Esnaola S, Rubio R, Iztueta A. Obstructive sleep apnea-hypopnea and related clinical features in a population-based sample of subjects aged 30 to 70 yr. Am J Respir Crit Care Med 2001;163:685-689.

3. Floras JS. Hypertension and sleep apnea. Can J Cardiol 2015;31:889-897.

4. Reutrakul S, Mokhlesi B. Obstructive sleep apnea and diabetes: a state of the art review. Chest 2017;152:1070-1086.

5. Ryan S. Adipose tissue inflammation by intermittent hypoxia: mechanistic link between obstructive sleep apnoea and metabolic dysfunction. J Physiol 2017;595:2423-2430.

6. Liguori C, Mercuri NB, Izzi F, Romigi A, Cordella A, Piccirilli E, et al. Obstructive sleep apnoea as a risk factor for osteopenia and osteoporosis in the male population. Eur Respir J 2016;47:987-990.

7. Sharma S, Culebras A. Sleep apnoea and stroke. Stroke Vasc Neurol 2016;1:185-191.

8. Lutsey PL, Misialek JR, Mosley TH, Gottesman RF, Punjabi NM, Shahar E, et al. Sleep characteristics and risk of dementia and Alzheimer's disease: the Atherosclerosis Risk in Communities Study. Alzheimers Dement 2018;14:157-166.

9. Xie L, Kang H, Xu Q, Chen MJ, Liao Y, Thiyagarajan M, et al. Sleep drives metabolite clearance from the adult brain. Science 2013;342:373-377.

10. Osorio RS, Ayappa I, Mantua J, Gumb T, Varga A, Mooney AM, et al. Interaction between sleep-disordered breathing and apolipoprotein $\mathrm{E}$ genotype on cerebrospinal fluid biomarkers for Alzheimer's disease in cognitively normal elderly individuals. Neurobiol Aging 2014;35:1318-1324.

11. Osorio RS, Gumb T, Pirraglia E, Varga AW, Lu SE, Lim J, et al.; Alzheimer's Disease Neuroimaging Initiative. Sleep-disordered breathing advances cognitive decline in the elderly. Neurology 2015; 84:1964-1971.

12. Ju YE, Finn MB, Sutphen CL, Herries EM, Jerome GM, Ladenson JH, et al. Obstructive sleep apnea decreases central nervous system-derived proteins in the cerebrospinal fluid. Ann Neurol 2016;80:154-159.

13. Yun CH, Lee HY, Lee SK, Kim H, Seo HS, Bang SA, et al. Amyloid burden in obstructive sleep apnea. J Alzheimers Dis 2017;59:21-29.

14. Sharma RA, Varga AW, Bubu OM, Pirraglia E, Kam K, Parekh A, et al. Obstructive sleep apnea severity affects amyloid burden in cognitively normal elderly: a longitudinal study. Am J Respir Crit Care Med 2018;197:933-943.

15. Liguori C, Mercuri NB, Izzi F, Romigi A, Cordella A, Sancesario G, et al. Obstructive sleep apnea is associated with early but possibly modifiable Alzheimer's disease biomarkers changes. Sleep (Basel) 2017;40:zsx011.

16. Liguori $C$, Chiaravalloti A, Izzi F, Nuccetelli M, Bernardini S, Schillaci $O$, et al. Sleep apnoeas may represent a reversible risk factor for $A \beta_{42}$ pathology. Brain 2017;140:e75.

Copyright (C) 2018 by the American Thoracic Society 